\title{
The Use of Information Technology toward Online Transaction in Micro Enterprise using Technology Acceptance Model (TAM) Framework
}

\author{
Sami Ghait Abdulgader \\ Magister of Information System \\ Diponegoro University
}

\author{
Suryono \\ Magister of Information System \\ Diponegoro University
}

\author{
Jatmiko Endro Suseno \\ Magister of Information System \\ Diponegoro University
}

\begin{abstract}
Technology Acceptance Model (TAM) is an adaptation of TRA introduced by Davis. The purpose of TAM is devoted to explaining the behavior of the users computer (computer usage behavior). The importance of internet and of the TAM antecedents of its website, however, change with experience. Aim of this study was to design and analysis the use of technology toward online transaction using TAM framework. In this research, the design of website of micro enterprises using TAM Framework. The sample is 15 respondents who make transaction online in Semarang. The method analysis use in this research is descriptive analysis. In this research used some technologies like: HTML, this is the basis of website. The result of this study HTML and CSS are used for the rapidly responsive website design. The results of the analysis are known that most of the respondents agreed on the use of online transaction technology using TAM framework. New findings/significance of contribution almost all respondents agreed to answer the TAM framework applied in website design to facilitate online transactions.
\end{abstract}

\section{Keywords}

Information, technology, online transaction, TAM framework

\section{General Terms}

Design of website

\section{INTRODUCTION}

Internet is a medium that fastest and most accurate in providing information. Internet is one of the product and services that are very easy to operate and can be used by all circles and can be used all the time that excess which became one of the factors driving the development of the internet throughout world [1] Technology Acceptance Model (TAM) is an adaptation of TRA introduced by Davis. The purpose of TAM is devoted to explaining the behavior of the users computer (computer usage behavior). The importance of internet and of the TAM antecedents of its website, however, change with experience. In an initial interaction, the assessment of whether another person or organization, in general, can be trusted depends, generally speaking, on a permeating disposition to trust that develops through lifelong socialization. Once interaction with the trusted party takes place, this disposition is mitigated [2]

Micro enterprises are key drivers of economic growth, providing employment, providing market linkages across various sectors, promoting innovation, reducing poverty and contributing to GDP in both developed and developing countries [3]
This contributes to the low prevalence of new venture creation, low graduation rates and ultimately the high failure rate among microenterprises [4].

Three main insights concerning the determinant of managerial computer use which are: firstly, people's computer use can be predicted reasonably well from their intention, secondly, perceived usefulness is a major determinant of people's intention to use computer, thirdly, perceived ease of use as a significant secondary determinant of people's intention to use computer [5]

TAM to explain acceptance of information technology (IT). It was relied on TRA (the Theory of Reasoned Action) and its contents intention and behavior to use an information system which depends on two salient beliefs, namely perceived usefulness and ease of use. A key purpose of TAM is to provide a basis for tracing the impact of external factors on internal beliefs, attitude and intention, more TAM consist that two particular beliefs, perceived usefulness and perceived ease of use are primary relevance for computer acceptance behaviors [6]

\section{RELATED WORK}

Based on established pertinent theoretical foundations and literature, a research model has been employed to investigate the technology acceptance factors that influence the adoption of online shopping within the context of Malaysian consumers. The TAM has emerged as a powerful model in investigating the acceptance and use of information technology [7] The choice for using TAM as a research model to explain consumers' online shopping adoption is attributed to its consistent capability to explain a substantial portion of variances between behavioral intention and actual behaviors derived mainly from research into the purchase of technology related products [8]

\section{RESEARCH METHODOLOGY 3.1 Material and Method}

In this research, will make the design of website of micro enterprises using TAM Framework. The sample is 15 respondents who make transaction online in Semarang. The method analysis use in this research is descriptive analysis. In this research will use design to make website planning. In the planning and designing web site, then building the HTML and CSS will be easier. In this research will use some technologies like: HTML, this is the basis of website.

\subsection{Research Procedure}

In this research there are some steps of the study, such as:

\section{Planning and identification problem}


Planning is the framework to make analysis with TAM Framework. In design and implementation commercial website the steps as follows:

a. To design the commercial website, first the researcher should look for:

1) Text - this can be articles, blog posts, lists, reviews, or anything that want to write about on website.

2) Graphics - there are lots of places to find images for web pages including photos that have taken and free images. Be sure using the right format for your images.

3) Multimedia - Remember that multimedia can have a negative impact on website. Make sure that when adding sound and video to web sites appropriately. Multimedia isn't appropriate for all target audiences.

b. If you've done a good job planning and designing web site, then building the HTML and CSS will be easier. In this research will use some technologies like: HTML, this is the basis of website.
2. System Analysis

The analysis will use by questionairres. A questionnaire is a research instrument consisting of a series of questions and other prompts for the purpose of gathering information from respondents.

\begin{tabular}{|l|c|}
\hline \multicolumn{1}{|c|}{ Answer Option } & Point \\
\hline Strongly Agree & 5 \\
\hline Agree & 4 \\
\hline Neutral & 3 \\
\hline Disagree & 2 \\
\hline Strongly Disagree & 1 \\
\hline
\end{tabular}

3. Samples

The samples is 15 customers who make online transaction in Semarang.

4. Descriptive analysis

Descriptive analysis is one of the method that used to know the use of technology toward online transaction using TAM framework.

\subsection{System framework}

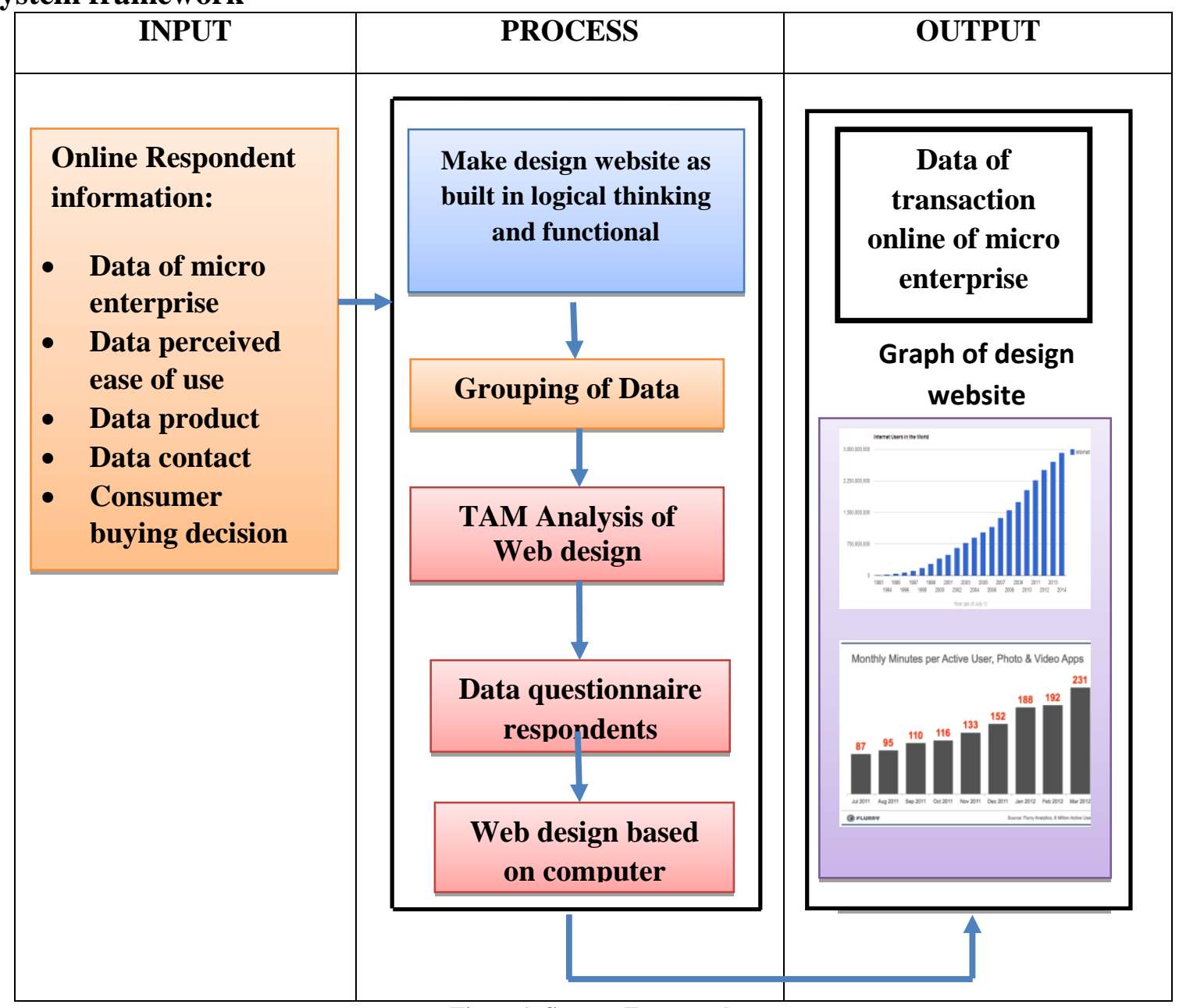

Figure1. System Framewok

\section{RESULT}

\subsection{Design Online Transaction}

Web site design of online transactions on this research is designed by a plying modern concepts with cheerful and elegant nuances. The concept of this promotional media presents a combined illustration of photographs of products from online shops that will be sold. The design of the online shop is made simple by considering the aspects of beauty, so it will look interesting when viewed by prospective customers. 
The appearance of the online shop is made simple (minimalist) by presenting any menu dish, namely: shop, chart, checkout.
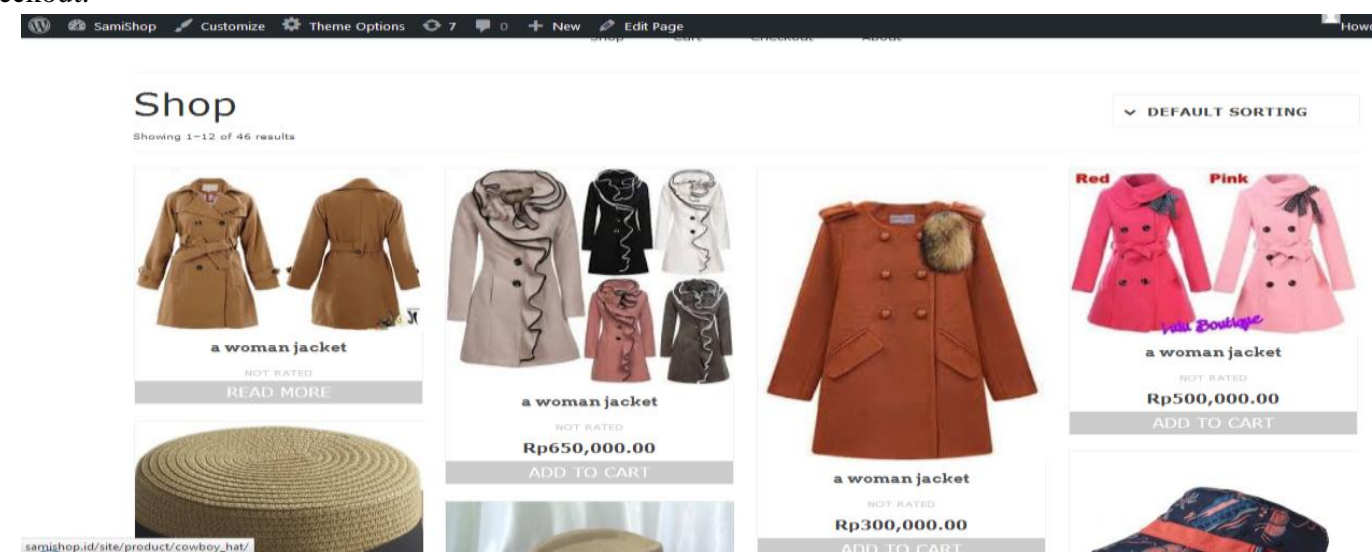

Figure2. Display Menu Shop in Online Shop

\section{Cart}
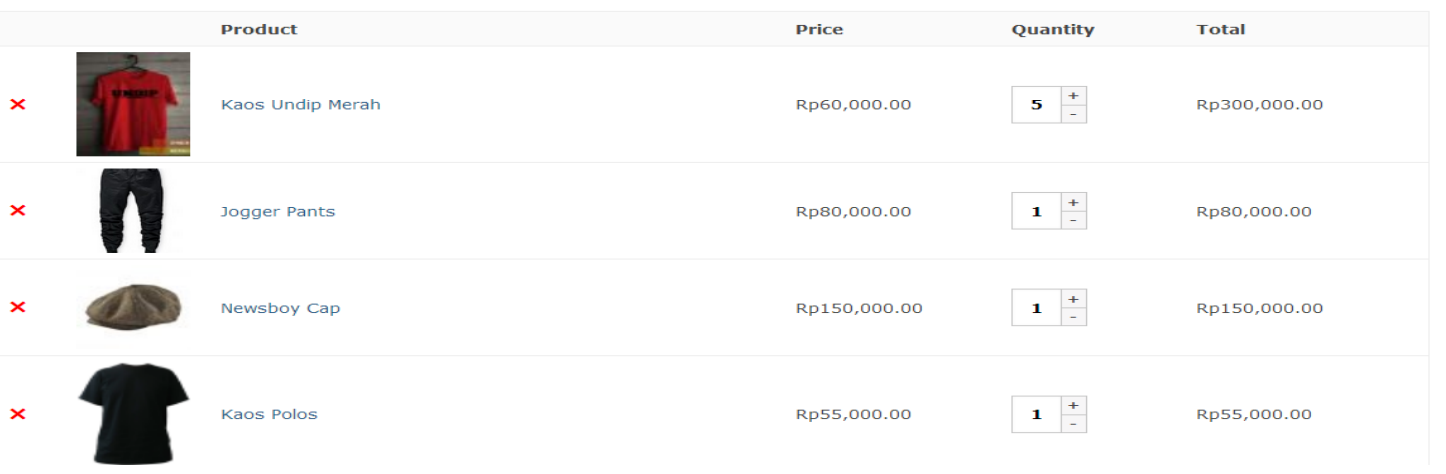

\section{Cart totals \\ Proceed to checkout}

Figure 3. Display Menu Chart in Online Shop

A modern website is a tool for any company to increase its visibility to potential customers. HTML and CSS are used for the rapidly responsive website design. In this research, website design using basic HTML and CSS. Media requests are CSS technology, consisting of syntax and at least one expression that limits sheet style coverage by using media features, such as width, height, and color. Media requests allow CSS to be applied only when certain conditions are met. Media queries can be written that will only execute CSS, if the browser reaches a certain width. This means that if the design is too large or too small, the media query can be used to detect the width of the site and present the CSS that reset the site content correctly. Figure 4 . is the design of the media query used. 


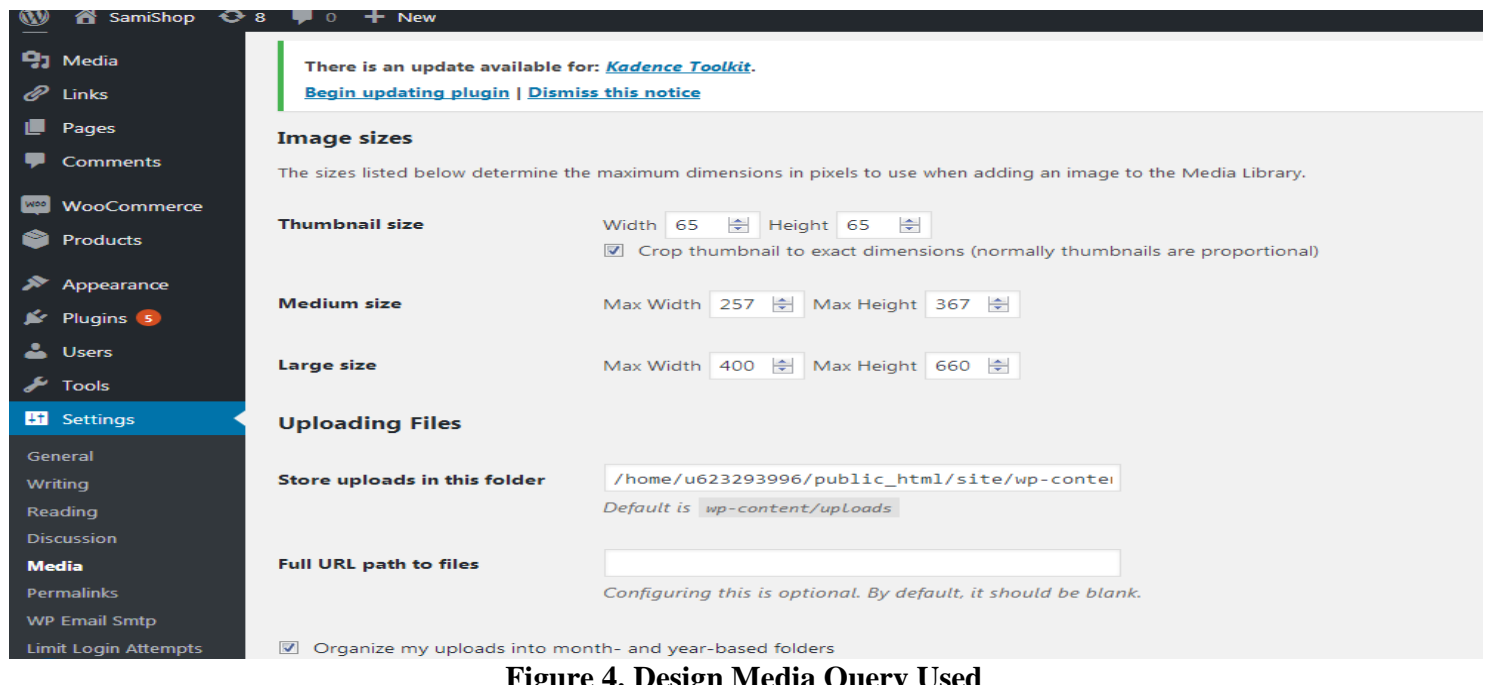

Figure 4. Design Media Query Used

4.2 Analysis Online Transaction Using

TAM Framework

a. Demographic

\section{Gender}

Data of respondents characteristic based on the gender served in the figure 5 :
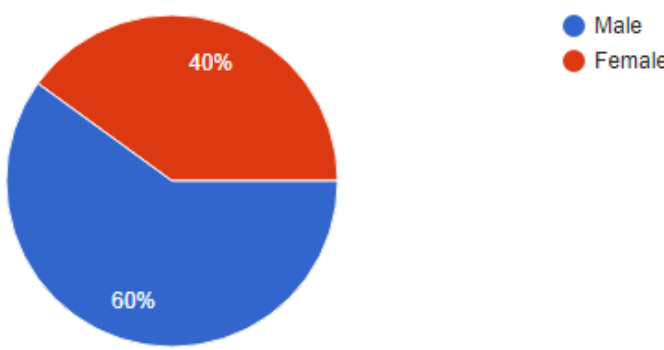

Figure 5. Gender of Respondent

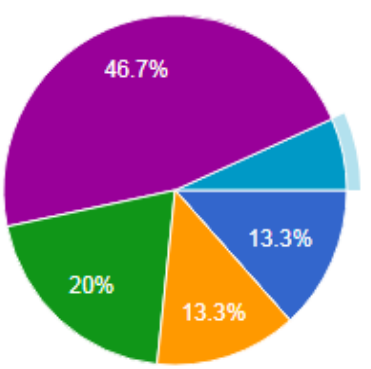

$<17$ years old

17-20 years old

21-23 years old

24-25 years old

$>25$ years old

23-25 years old

\section{Figure 6. Age of Respondent}

Figure 5. presents the number of male respondents is 9 respondents or $60 \%$ whereas the female respondents is 6 respondents about $40 \%$ of the populations. Thus the most number of respondents is male respondents with the number of 9 persons or $60 \%$

\section{Age}

Data of respondent characteristic based on the age can be seen in the Figure 5. Regarding to the Figure 4.5 bellow, we can figure out that the respondents in the age less than 17 years old is 3 respondents or $20 \%$, more than $21-23$ years old is 2 or $13.30 \%$, more than $24-25$ years old is 3 respondents or $20 \%$ and more than 25 years old is 7 respondents or $46.70 \%$.

\subsection{Descriptive Analysis}

Analysis of online transactions using TAM framework is done using descriptions of data from questionnaires that are asked to consumers from online shop. Table 1 and figure 6 below is a description of data from the respondent's answer.

\begin{tabular}{|l|l|r|r|r|r|}
\hline \multirow{2}{*}{ Variable } & \multicolumn{1}{|c|}{ Indicator } & \multicolumn{3}{c|}{ Data Description } \\
\cline { 3 - 6 } & & Mean & \multicolumn{1}{|c|}{ Max } & \multicolumn{1}{c|}{ Min } & Mode \\
\hline \multirow{5}{*}{ Perceived use } & Is the website attractive? & 3.80 & 5 & 1 & 4 \\
\cline { 2 - 6 } & $\begin{array}{l}\text { Is the website contains more information that } \\
\text { very useful? }\end{array}$ & 3.80 & 5 & 1 & 4 \\
\cline { 2 - 6 } & $\begin{array}{l}\text { Is the transaction through the website is very } \\
\text { easy? }\end{array}$ & 3.86 & 5 & 3 & 4 \\
\cline { 2 - 6 } & Is the website well designed? & 3.86 & 5 & 2 & 4 \\
\cline { 2 - 6 } & Is the website user friendly? & 3.80 & 5 & 1 & 4 \\
\cline { 2 - 6 } & Is the website easy to use? & & 5 & 1 \\
\hline
\end{tabular}




\begin{tabular}{|l|l|r|r|r|r|}
\hline & Is the website sell a lot varian of products? & 3.67 & 5 & 1 & 4 \\
\hline \multirow{2}{*}{$\begin{array}{l}\text { Perceived } \\
\text { of-use }\end{array}$} & Is the satisfactory product? & 3.73 & 5 & 1 & 4 \\
\cline { 2 - 5 } & Is the contact/data Easily found & 3.53 & 5 & 1 & 4 \\
\hline $\begin{array}{l}\text { External } \\
\text { Variable }\end{array}$ & Gender & 1.33 & 2 & 1 & 1 \\
\cline { 2 - 5 } & Age & 3.73 & 1 & 5 & 5 \\
\hline Attitude towards & I read other people's comments before buying & 3.47 & 1 & 5 & 5 \\
\cline { 2 - 5 } & $\begin{array}{l}\text { I am content to choose social media as a place } \\
\text { shop }\end{array}$ & 3.86 & 1 & 5 & 5 \\
\cline { 2 - 6 } & Service response provided very quickly & 3.67 & 1 & 5 & 4 \\
\hline $\begin{array}{l}\text { Behavioral } \\
\text { intention to use }\end{array}$ & The experience of others influence me in buying & 3.60 & 1 & 5 & 4 \\
\hline Actual use & I was compelled to buy & & & \\
\hline
\end{tabular}

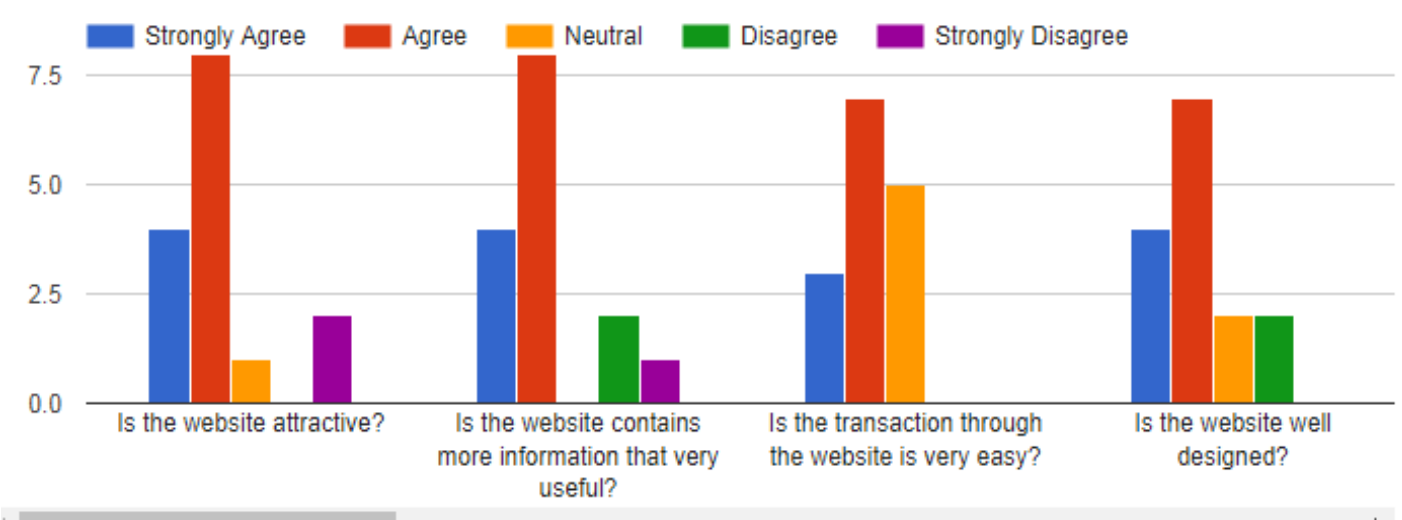

Figure 7. 1 Graph of the Answer Questionnaire (a: answer indicator 1-4; b: answer indicator 5-8)

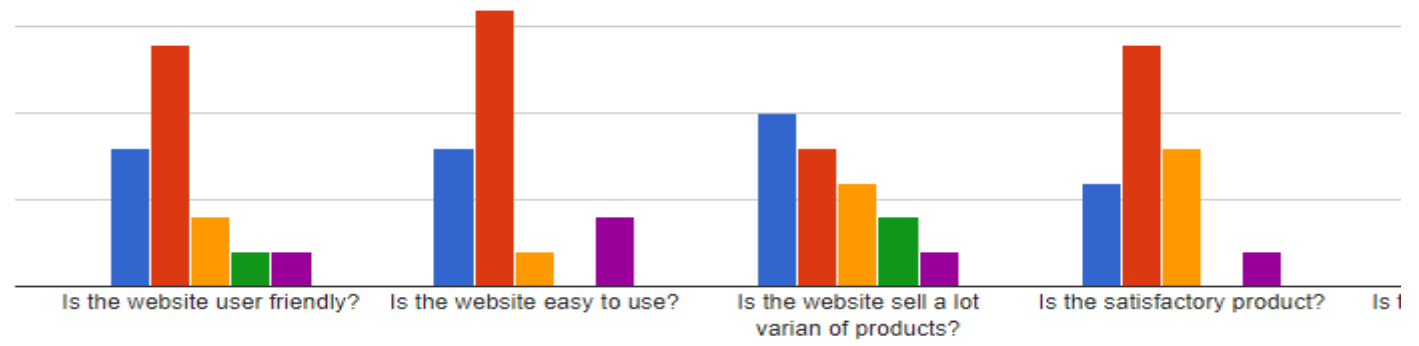

Figure 7.2 Graph of the Answer Questionnaire (a: answer indicator 1-4; b: answer indicator 5-8)

Based on the descriptive table of data (table 1 and Figure 7) it can be seen that the Perceived usefulness (PU) variable is known that the answer of the maximum respondent is 5 and the minimum is 1 whereas the mode or answer that often appears is 4 that means agree. In Perceived ease-of-use (PEOU) that the answer of the respondent maximum is 5 and the minimum is 1 whereas the mode or answer that often appear is 4 that means agree. For External variable as well as the gender of the respondents answer that mostly appear is 1 that is male and age that often appear is 5 that's means the age more than 25 years old.

\section{CONCLUSION}

1. Responsive designing is a great idea for those who want their website easy for users to access. It is difficult to compete with different devices and resolutions on the market. Responsive web design adjusts web pages with different screen sizes and is also set up for future devices that have not yet been released. Along with the many mobile devices, the importance of responsive web design is also increasing. It's important for business or business websites to be optimized for the optimal user experience without major changes in flow, navigation and content. Responsive web design implementation can result in more visitors, increased sales and customer satisfaction. In this study, web design used using HTML and CSS to support the application of TAM framework on the concept of online transactions.

2. Within the TAM framework, assessing the settings of online transactions requires users to constantly and 
appropriately think outside, to obtain and utilize online transactions from online stores, and to use websites to facilitate online transactions. Based on the results of research, almost all respondents agreed to answer the TAM framework applied in website design to facilitate online transactions.

\section{REFERENCES}

[1] Chen, Y.T. and Chou, T.Y. 2012. Exploring the Continuance Intentions of Consumers for B2C Online Shopping: Perspectives of Fairness and Trust. Online Information Review, Vol. 36, No. 1:104-125.

[2] Zimmer, J.C., Arsal, R.E., Al-Marzouq, M., and Grover, V. 2012. Investigating Online Information Disclosure: Effects of Information Relevance, Trust and Risk. Information \& Management, Vol. 47, No. 2:115-123.

[3] Cole, S., Thomas, S., and Bilal, Z. 2013. Prices or Knowledge? What Drives Demand for Financial Services in Emerging Markets? Harvard Business School Finance Working Paper Series. October.

[4] Mengich, H. Ndalira, F. and Juma, F. 2013. Challenges facing uptake of equity financing by small and microenterprises in Kenya: A Case Study Of Small
Financial Services Enterprises in Nairobi County: International Journal of Innovative Research and Development. Vol.2 Issue 10.

[5] Chang, Y.S. and Fang, S.R. 2013. Antecedents And Distinctions Between Online Trust And Distrust: Predicting High- And Low-Risk Internet Behaviors. Journal of Electronic Commerce Research, Vol. 14, No. 2.

[6] Chang, Y.S. and Fang, S.R. 2013. Antecedents And Distinctions Between Online Trust And Distrust: Predicting High- And Low-Risk Internet Behaviors. Journal of Electronic Commerce Research, Vol. 14, No. 2 .

[7] Chang, Y.S. and Fang, S.R. 2013. Antecedents And Distinctions Between Online Trust And Distrust: Predicting High- And Low-Risk Internet Behaviors. Journal of Electronic Commerce Research, Vol. 14, No. 2.

[8] Hague, A., Sadeghzadah, J., and Khatibi, A. 2016 Identifying potentiality online sales in Malaysia: a study on customer relationships online shopping. Journal of Applied Business Research, 22(4), 119. 